\title{
Inhibition of $\psi$-secretase worsens memory deficits in a genetically congruous mouse model of Danish dementia
}

\author{
Robert Tamayev ${ }^{\dagger}$ and Luciano D'Adamio ${ }^{*}$
}

\begin{abstract}
Background: A mutation in the BRI2/ITM2b gene causes familial Danish dementia (FDD). BRI2 is an inhibitor of amyloid- $\beta$ precursor protein (APP) processing, which is genetically linked to Alzheimer's disease (AD) pathogenesis. The FDD mutation leads to a loss of BRI2 protein and to increased APP processing. APP haplodeficiency and inhibition of APP cleavage by $\beta$-secretase rescue synaptic/memory deficits of a genetically congruous mouse model of FDD (FDD $\left.{ }_{K I}\right)$. $\beta$-cleavage of APP yields the $\beta$-carboxyl-terminal $(\beta-C T F)$ and the amino-terminal-soluble APP $\beta$ (SAPP $\beta$ ) fragments. $\gamma$-secretase processing of $\beta$-CTF generates $A \beta$, which is considered the main cause of AD. However, inhibiting $A \beta$ production did not rescue the deficits of $F D D_{K I}$ mice, suggesting that $S A P P \beta / \beta-C T F$, and not $A \beta$, are the toxic species causing memory loss.

Results: Here, we have further analyzed the effect of $y$-secretase inhibition. We show that treatment with a $\gamma$-secretase inhibitor (GSI) results in a worsening of the memory deficits of $\mathrm{FDD}_{\mathrm{KI}}$ mice. This deleterious effect on memory correlates with increased levels of the $\beta / A-C T F S$ APP fragments in synaptic fractions isolated from hippocampi of FDD $D_{K I}$ mice, which is consistent with inhibition of $\gamma$-secretase activity.

Conclusion: This harmful effect of the GSI is in sharp contrast with a pathogenic role for $A \beta$, and suggests that the worsening of memory deficits may be due to accumulation of synaptic-toxic $\beta /$ a-CTFs caused by GSI treatment. However, $\gamma$-secretase cleaves more than 40 proteins; thus, the noxious effect of GSI on memory may be dependent on inhibition of cleavage of one or more of these other $\gamma$-secretase substrates. These two possibilities do not need to be mutually exclusive. Our results are consistent with the outcome of a clinical trial with the GSI Semagacestat, which caused a worsening of cognition, and advise against targeting $y$-secretase in the therapy of $A D$. Overall, the data also indicate that $F D D_{K I}$ is a valuable mouse model to study $A D$ pathogenesis and predict the clinical outcome of therapeutic agents for AD.
\end{abstract}

\section{Background}

$\mathrm{AD}$ is characterized by amyloid deposition of $\mathrm{A} \beta$ peptides that derive from sequential cleavage of APP by $\beta$ - and $\gamma$-secretases [1,2]. Mutations in APP cause familial AD (FAD) [3]. Familial dementia is also caused by mutations in genes that regulate APP processing. These include the PSEN1/2 genes, which code for the catalytic component of the $\gamma$-secretase, and the BRI2/ITM $2 b$ gene, whose protein product BRI2 binds APP and inhibits APP processing [3-10]. Although the familial cases

\footnotetext{
*Correspondence: luciano.dadamio@einstein.yu.edu

${ }^{+}$Equal contributors

Department of Microbiology \& Immunology, Albert Einstein College of Medicine, Bronx, NY 10461, USA
}

caused by $A P P / P S E N$ mutations are classified as FAD and those caused by mutations in BRI2/ITM2 $b$ as Familial Danish or British dementias (FDD or FBD), recent evidence suggest that FBD and FDD share with FAD a pathogenic mechanism involving synaptic-toxic APP metabolites released during memory acquisition [11-16].

The prevailing pathogenic model for these dementias, the amyloid cascade hypothesis, posits that amyloid peptides, in forms of either amyloid plaques or oligomers, trigger dementia. In the case of $\mathrm{AD}$, the amyloid peptide is $A \beta$, which is a part of APP and is also present in normal individuals; in the case of FDD and FBD the amyloidogenic peptides, called ADan and ABri respectively, are generated from the mutant BRI2 proteins

\section{Biomed Central}

(c) 2012 Tamayev and D'Adamio; licensee BioMed Central Ltd. This is an Open Access article distributed under the terms of the Creative Commons Attribution License (http://creativecommons.org/licenses/by/2.0), which permits unrestricted use, distribution, and reproduction in any medium, provided the original work is properly cited. 
$[4,10]$ and are not present in normal individuals. Notably, the FDD amyloid plaques contain both $\mathrm{A} \beta$ and ADan. Based on the amyloid cascade hypothesis [17], transgenic mice carrying mutant APP, PSEN1/2 or $B R I 2 / I T M 2 b$ are used to model these dementias, as over-expression is necessary to reproduce amyloidosis [18]. However, over-expression of mutant genes produce harmful effects unrelated to AD leading to erroneous information concerning pathogenesis and therapy of human diseases.

To avoid artifacts of over-expression, we generated a knock-in mouse model of FDD (FDD $\left.{ }_{\mathrm{KI}}\right)$ that, like FDD patients [10], carries a wild type Bri2/Itm $2 b$ allele and the other with the Danish mutation [19]. FDD KI $_{\text {mice de- }}$ velop progressive synaptic and memory deficits due to loss of Bri2, but do not develop amyloidosis [13]. BRI2 binds to APP and inhibits cleavage of APP by secretases [6-9]. Owing to the loss of BRI2, processing of APP is increased in FDD $[11,12]$. Remarkably, memory and synaptic deficits of $\mathrm{FDD}_{\mathrm{KI}}$ mice require APP [12], and more specifically processing of APP by $\beta$-secretase during synaptic plasticity and memory acquisition $[15,16]$. The two products of $\beta$-processing of APP are $\operatorname{sAPP} \beta$ and $\beta$-CTF. The latter is processed by $\gamma$-secretase to yield $A \beta$. Contrary to the amyloid hypothesis of AD pathogenesis, inhibition of $\gamma$-secretase did not ameliorate synaptic/ memory deficits of FDD $_{\mathrm{KI}}$ mice $[15,16]$. Overall, these results provide genetic evidence that APP and BRI2 functionally interact and that APP mediates FDD neuropathology, and suggest that SAPP $\beta$ and/or $\beta-C T F$, rather than $\mathrm{A} \beta$, are the toxic species causing dementia. Here, we have evaluated further the role of $\gamma$-secretase in the pathogenesis of memory deficits of FDD $\mathrm{KI}_{\mathrm{I}}$ mice.

\section{Results}

Inhibiting $\mathrm{Y}$-cleavage of APP does not rescue the memory deficit of $F D D_{\mathrm{KI}}$ mice

To test the role of $\gamma$-secretase in the pathogenesis of agingdependent memory deficits developed by $\mathrm{FDD}_{\mathrm{KI}}$ mice [13], a cannula was surgically implanted in the lateral ventricle of a cohort of 9-month-old FDD $_{\mathrm{KI}}$ mice and WT littermates. Four weeks post-surgery, we analyzed the memory deficits of $\mathrm{FDD}_{\mathrm{KI}}$ mice using novel object recognition (NOR), a non-aversive memory test that relies on the mouse's natural exploratory behavior. Prior to the NOR tests, open field studies showed, as previously reported [13], that FDD $_{\mathrm{KI}}$ mice have no defects in habituation, sedation, risk assessment and anxiety-like behavior in novel environments. First, the mice were studied without treatments. The NOR test showed that during training, FDD $_{\mathrm{KI}}$ and WT mice spent the same amount of time exploring two identical objects (Figure 1a). The following day, when one of the two old objects was replaced with a new one, WT mice preferentially explored the novel object; on the other hand FDD $\mathrm{KI}_{\mathrm{I}}$
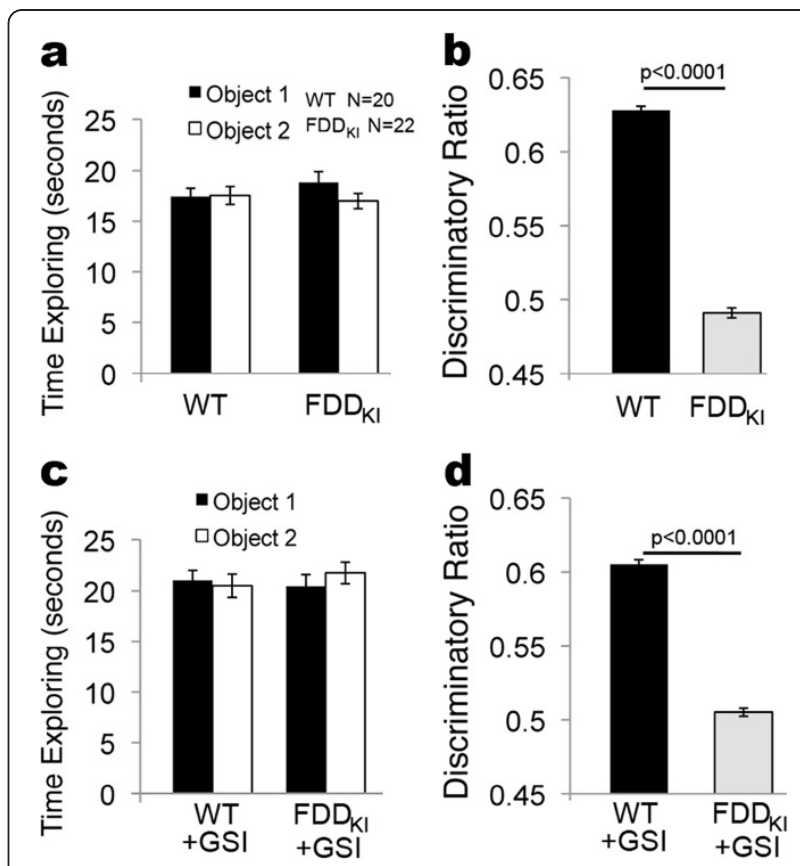

Figure 1 Inhibiting $\boldsymbol{\gamma}$-secretase does not rescue the memory deficit of $\mathrm{FDD}_{\mathrm{KI}}$ mice. a. FDD $\mathrm{KI}_{\mathrm{I}}$ and $\mathrm{WT}$ mice were cannulated. Four weeks after cannulation mice were subjected to a NOR test. Untreated $W T$ and $F D D_{K I}$ mice spent the same amount of time exploring the two identical objects on day 1. b. WT mice spent more time exploring the novel object 24 hours later, showing normal object recognition (discriminatory ratio $=0.63$ ), while $F D D_{K I}$ mice present amnesia and do not distinguish the new object from the old one (discriminatory ratio=0.5). c. A week after the first NOR, mice were injected in the lateral ventricle with $1 \mu$ of $P B S / 3 \mu \mathrm{M}$ compound-E. Injections were performed $1 \mathrm{hr}$ prior to the training section, which shows that both treated groups explore equally the two identical objects. $\mathbf{d}$. The following day, $1 \mathrm{hr}$ before testing mice were injected in the lateral ventricle with $1 \mu \mathrm{l}$ of $\mathrm{PBS} / 3 \mu \mathrm{M}$ compound-E. The GSI neither rescued the memory deficit of FDD $\mathrm{KI}_{\mathrm{K}}$ mice nor it changed memory of WT animals.

mice spent the same amount of time exploring the two objects as if they were both novel to them, showing that they had no memory of the objects from the previous day (Figure 1b). This data further confirms the amnesia caused by the FDD mutation in one of the two Bri2/Itm $2 b$ mouse alleles.

One week later, we tested the mice again to determine whether the GSI compound-E could rescue this amnesic phenotype. To this end, these same animals were injected $1 \mathrm{hr}$ before the training with $1 \mu \mathrm{l}$ of a $3 \mu \mathrm{M}$ solution of compound-E in PBS. Again, both treated WT and $\mathrm{FDD}_{\mathrm{KI}}$ mice spent similar times exploring the two identical objects on day 1 (Figure 1c). One day later, mice were again injected with $1 \mu \mathrm{l}$ of a $3 \mu \mathrm{M}$ solution of compound-E in PBS $1 \mathrm{hr}$ before the testing section with the new object. In agreement with what we have previously shown $[15,16]$ the GSI neither improved memory 
of $\mathrm{FDD}_{\mathrm{KI}}$ mice nor altered performance of WT animals (Figure 1d).

\section{Inhibiting $\mathrm{Y}$-secretase worsens the memory deficit of $\mathrm{FDD}_{\mathrm{KI}}$ mice}

In the NOR paradigm used, the memory for the old objects is tested $24 \mathrm{hrs}$ after the initial exposure to these objects. With this delay, $\mathrm{FDD}_{\mathrm{KI}}$ mice show complete amnesia. We tested whether younger $\mathrm{FDD}_{\mathrm{KI}}$ mice show memory deficits when the novel object is showed to the

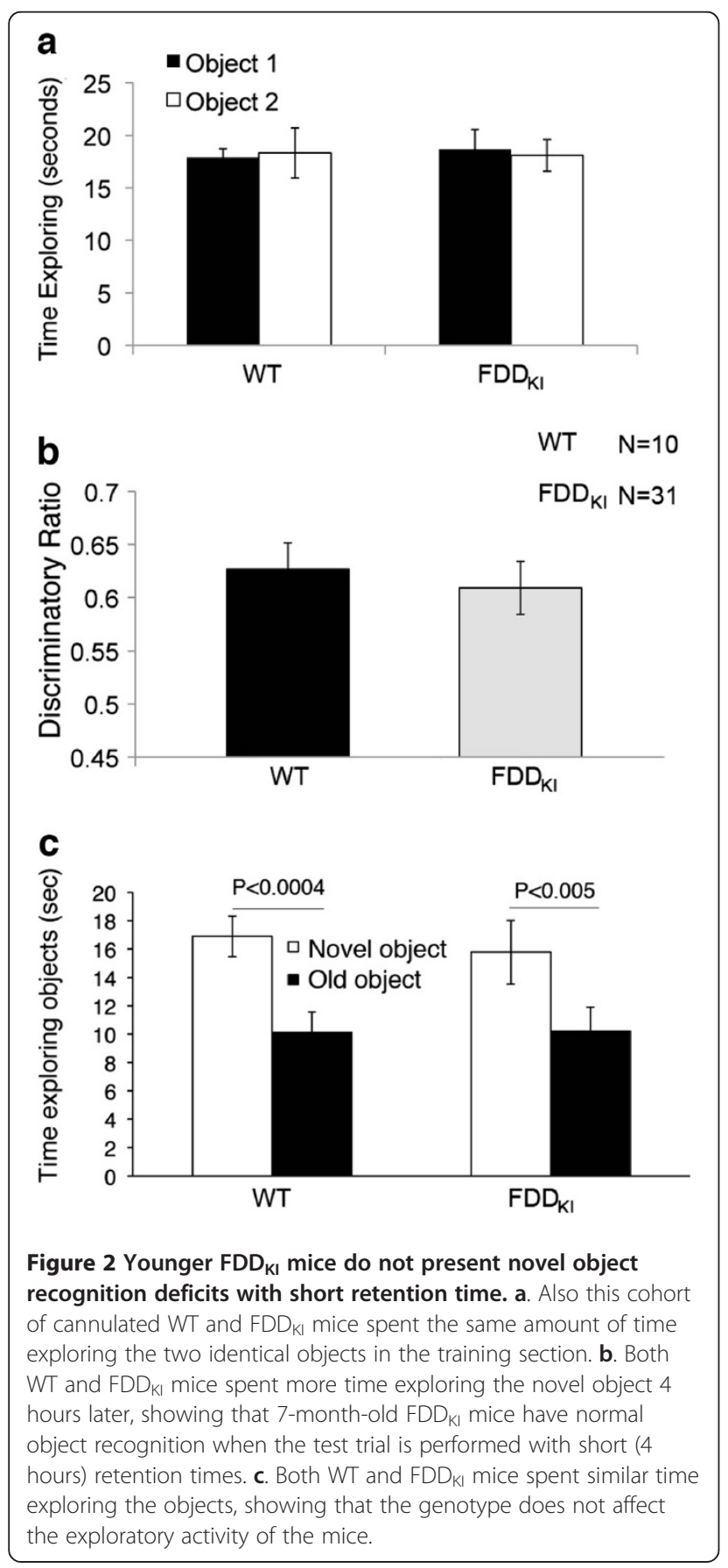

mice four hours after the training trial with the two identical objects. Cannulas were surgically implanted in the lateral ventricle of a new cohort of 5/6-month-old FDD $_{\mathrm{KI}}$ mice and WT littermates. At this age, $\mathrm{FDD}_{\mathrm{KI}}$ mice already show memory deficits [13]. Three weeks after the surgery, we performed a NOR experiment with a 4 hours delay between the training test with the two identical objects, and
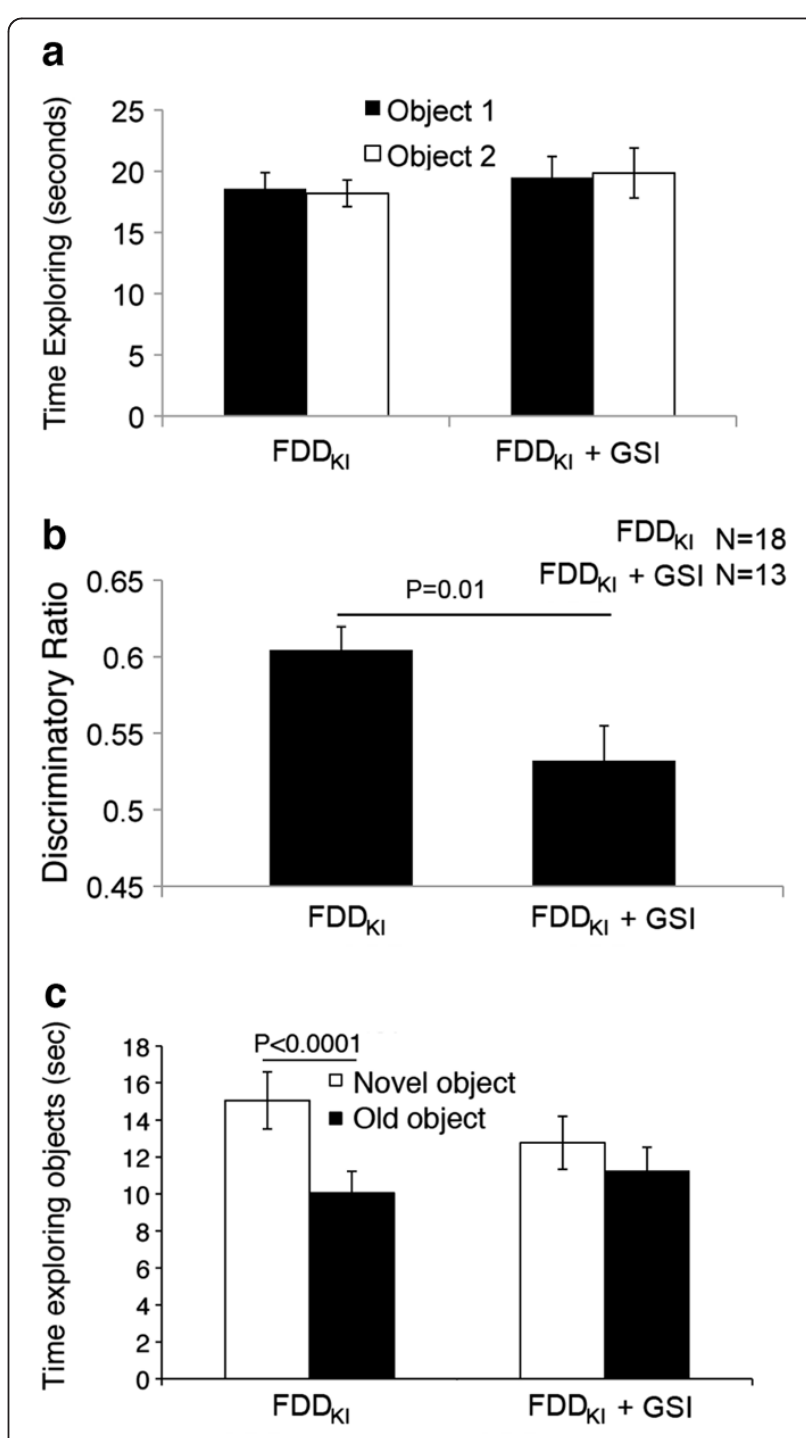

Figure 3 Inhibiting $\boldsymbol{Y}$-secretase worsens the memory deficit of $\mathrm{FDD}_{\mathrm{KI}}$ mice. Mice were injected in the lateral ventricle with either

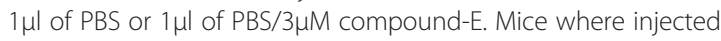
once, 1 hour prior to the training. $\mathbf{a}$. FDD $\mathrm{FI}_{\mathrm{KI}}$ mice, regardless of whether they were injected with vehicle alone of GSI, spent the same amount of time exploring the two identical objects in the training trial. $\mathbf{b}$. FDD $\mathrm{KI}_{\mathrm{KI}}$ mice injected with PBS spent more time exploring the novel object 4 hours later, showing normal object recognition, while $\mathrm{FDD}_{\mathrm{KI}}$ mice treated with GSI present a statistically significant novel object recognition deficit. c. There is no statistically significant difference in exploratory activity between treated and untreated $\mathrm{FDD}_{\mathrm{KI}}$ mice. 
the test trial with the new object. Again, during training $\mathrm{FDD}_{\mathrm{KI}}$ and WT mice explored the two identical objects equally (Figure 2a). When these mice were tested four hours later with the new object, both 6/7-month-old $\mathrm{FDD}_{\mathrm{KI}}$ and WT mice, preferentially explored the novel object (Figure 2b, c) and spend similar total times exploring each object (Figure 2c). Thus, in this experimental paradigm younger $\mathrm{FDD}_{\mathrm{KI}}$ mice show no memory deficits.

Having established that inhibition of $\gamma$-secretase does not ameliorate memory deficits of $\mathrm{FDD}_{\mathrm{KI}}$ mice (Figure 1d and $[15,16])$, we took advantage on this experimental setting in which $\mathrm{FDD}_{\mathrm{KI}}$ mice perform equally well as WT mice, to determine whether GSI could have a detrimental effect on memory. To this end, the day after the first NOR test shown in Figure 2, $\mathrm{FDD}_{\mathrm{KI}}$ mice were injected once, one hour before the training test, with either $1 \mu \mathrm{l}$ of PBS or $1 \mu \mathrm{l}$ of a $3 \mu \mathrm{M}$ solution of compound-E in PBS. GSI treated mice explored the two identical objects similarly to the PBS-treated animals (Figure 3a). When these mice were subjected to the trial test with the new object, GSI-treated FDD KI $_{\text {mice showed a statistically significant }}$ memory deficit as compared to vehicle-treated $\mathrm{FDD}_{\mathrm{KI}}$ mice (Figure 3b, c). Overall, these data show that inhibition of $\gamma$-secretase produces a worsening rather than amelioration of the memory deficit of FDD $_{\mathrm{KI}}$ mice. These data are consistent with the Phase III clinical trial with the GSI Semagacestat in AD patients.

\section{Inhibiting $Y$-secretase causes accumulation of APP-COOH-terminal fragments}

The dose of GSI injected $(1 \mu \mathrm{l}$ of a $3 \mu \mathrm{M}$ solution) was chosen based on the following rationale. $\mathrm{The} \mathrm{IC}_{50}$ for compound-E is $\sim 240 / 370 \mathrm{pM}$ (see manufacturer's website). We have estimated that after injection compound-E is diluted in the CSF of the lateral ventricles $~ 200$ folds (to approximately $15 \mathrm{nM}$, which is $\sim 50$ folds the $\mathrm{IC}_{50}$ ). Considering that clearance and distribution of the drugs in various area of the CNS further dilutes the GSI, it can be safely presumed that the concentration of the GSI in the hippocampus of mice during the course of the experiment was not excessively high. To determine whether this GSI dosage was sufficient to yield some level of inhibition of $\gamma$-secretase activity, we measured $\beta$-CTF and $\alpha-C T F$, which increase when $\gamma$-secretase is inhibited. Because novel object recognition is a hippocampal-dependent memory task and synaptic activity is associated with learning and memory, we measured the levels of these APP fragments in purified hippocampal synaptosomes. As shown in Figure 4a, b, the levels of both $\beta$-CTF and $\alpha$-CTF were significantly increased in mice treated for $5 \mathrm{~h}$ with compound-E as compared to untreated animals. In contrast, the levels of mature APP (mAPP, Figure 4a, b) and mature Bri2 (mBri2, Figure 4d, e) were unaffected by the GSI. The increase in APP-CTFs in hippocampal synaptic preparations resulted in significantly higher $\beta$-CTF/mAPP and $\alpha-C T F / m A P P$ ratios in GSI treated mice as compared to control mice (Figure 4c). These data indicate that injection of $1 \mu \mathrm{l}$ of a $3 \mu \mathrm{M}$ solution of compound-E was sufficient to measurably inhibit $\gamma$-secretase activity and processing of $\beta$-CTF and $\alpha$-CTF by $\gamma$-secretase.

\section{Discussion}

We have previously shown that the synaptic plasticity and memory deficits in FDD are mediated through production of sAPP $\beta$ and/or $\beta$-CTF during LTP and memory acquisition. The failure of GSI to rescue the deficits of 9/10-month-old FDD $_{\mathrm{KI}}$ mice $([15,16]$ and Figure 1d)
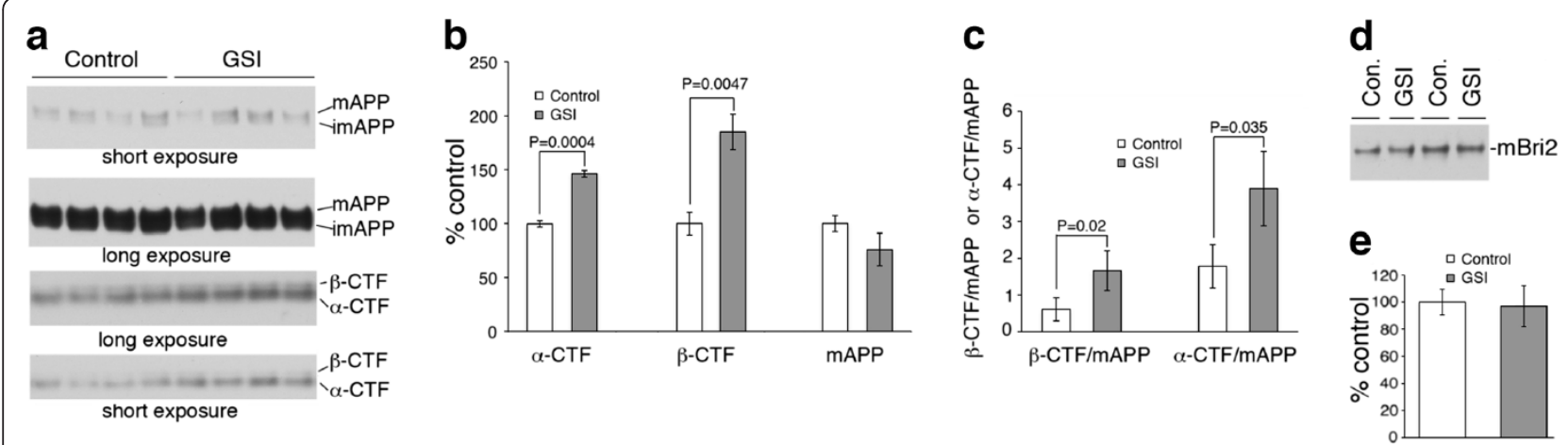

Figure 4 Inhibition of $\boldsymbol{\gamma}$-secretase causes an accumulation of $\beta$-CTF and $\alpha$-CTF in hippocampal synaptic preparations. a. Hippocampal

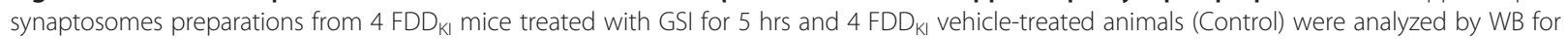
APP and CTFs. $\mathbf{b}$. Graph representing quantization of quadruplicate samples. The levels of $\beta$-CTF and a-CTF in vehicle-treated mice were assigned an arbitrary value of 100. The amounts of $\beta-C T F$ and a-CTF in treated samples were expressed as a \% of the levels in the control. Synaptic fractions from $G S I$ treated $F D D_{K I}$ mice express significantly more $a-C T F(P=0.0004)$ and $\beta-C T F(P=0.0047)$ than vehicle-treated samples. Similar

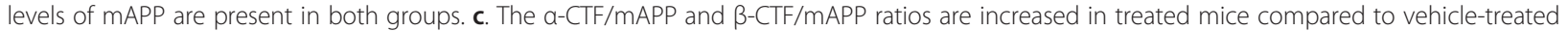
samples $\left(P=0.035\right.$ and $P=0.02$, respectively. $\mathbf{d}$. Synaptic fractions from both $G S I$ treated and vehicle-treated $F D D_{K I}$ mice express similar levels of mBri2. e. Quantization of mBRI2 levels in quadruplicate samples. 
suggests that $A \beta, P 3$ and AID/AICD, the metabolites derived from $\gamma$-cleavage of APP (Figure $5 \mathrm{a}, \mathrm{b}$ ), are not involved in these pathogenic processes. Younger $\mathrm{FDD}_{\mathrm{KI}}$ mice showed no memory deficits when subjected to NOR tests with a shorter (4 hours) retention time. Interestingly, GSI treatment of these mice provoked a memory deficit, which correlates with an accumulation of $\beta$-CTF and $\alpha$-CTF. Altogether, the data indicate that reducing $\gamma$-secretase activity is detrimental rather than beneficial in our mouse model of dementia. The evidence that PSEN1 and PSEN2 FAD mutations cause loss of $\gamma$-secretase function and that loss of Presenilins' function cause synaptic plasticity deficits, memory

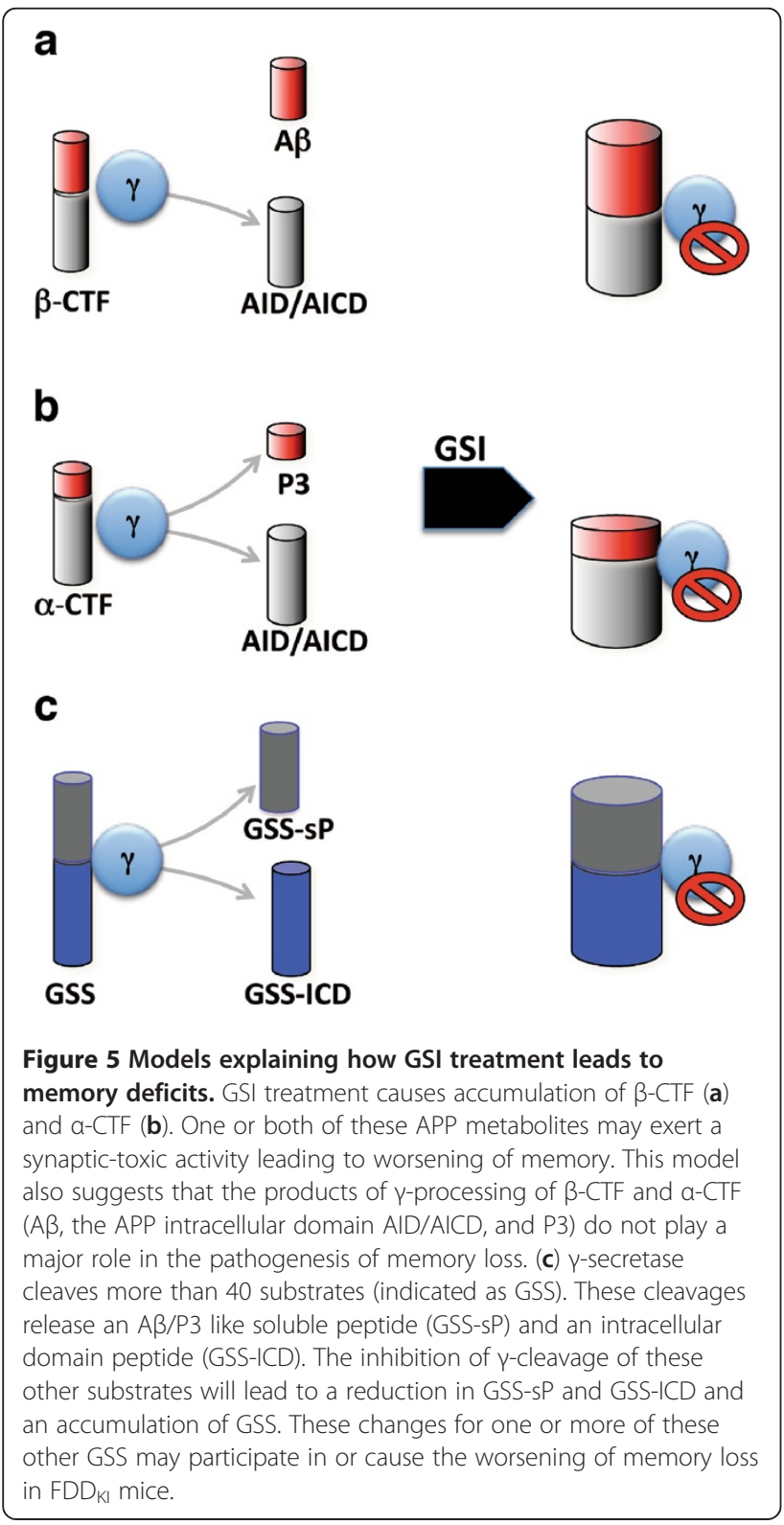

defects and neurodegeneration in mice [20-23] is consistent with these results.

The accumulation of $\beta$-CTF and $\alpha$-CTF caused by GSI treatment may prompt worsening of memory in $\mathrm{FDD}_{\mathrm{KI}}$ mice (Figure 5a, b). However, $\gamma$-secretase cleaves more than 40 substrates. Therefore, the toxic effect caused by GSI treatment may arise from inhibition of processing of other $\gamma$-secretase substrates (Figure 5c). These two hypotheses do not need to be mutually exclusive. Our data are concordant with two other set of evidence. First, a phase III clinical trial with Semagacestat, a $\gamma$-secretase inhibitor, was halted because Semagacestat rather than slowing disease progression caused a worsening of clinical measures of cognition and the ability to perform activities of daily living. Second, prolonged ( 8 days) treatment with GSIs produced no positive effects on memory deficits of older APP transgenic mice, and induced cognition deficits in both young APP transgenic mice and mice. These effects also correlated with accumulation of $\alpha / \beta$-CTFs [24].

In conclusion, this study suggests that targeting $A \beta$ production may be ineffective or, perhaps, detrimental. Importantly, our results once more show that our $\mathrm{FDD}_{\mathrm{KI}}$ model is useful to study pathogenic mechanisms of dementia and to test in preclinical studies the efficacy of candidate disease modifying drugs for AD.

\section{Material and methods}

\section{Mice}

Mice were generated and maintained at the Animal facility of the Albert Einstein College of Medicine. Mice were handled according to the Ethical Guidelines for Treatment of Laboratory Animals of Albert Einstein College of Medicine. The procedures were described and approved in animal protocol number 200404.

\section{Reagents}

Compound-e was purchased from (Calbiochem).

\section{Brain cannulation and injections}

Dr. Xiaosong Li at the Animal Physiology core of the Albert Einstein College of Medicine surgically implanted the cannula. Compound-E or PBS was delivered at the rate of $1 \mathrm{ml}$ per minute using a CMA 400 syringe pump.

\section{Open field and novel object recognition}

The mice were acclimated to the testing room for $30 \mathrm{~min}$ after being moved. Each mouse was placed into a $40 \mathrm{~cm} \mathrm{X}$ $40 \mathrm{~cm}$ open field chamber with opaque walls, $2 \mathrm{ft}$ high. Each mouse was allowed to habituate to the normal open field box for $10 \mathrm{~min}$, and repeated again $24 \mathrm{~h}$ later, in which the video tracking system (HVS 2020; HVS Image) quantified various locomotor parameters: total distance travelled, number of entries into, distance travelled in, and time spent in the centre of the locomotor arena. As 
previously reported [13], open field studies showed that $\mathrm{FDD}_{\mathrm{KI}}$ mice have no defects in habituation, sedation, risk assessment and anxiety-like behavior in novel environments.

Novel object recognition began $24 \mathrm{~h}$ after the second open field session, and was performed as previously described [13,25]. Briefly, NOR consisted of two sessions, either $24 \mathrm{~h}$ (Figure 1) or $4 \mathrm{~h}$ (Figures 2 and 3) apart. In the first session, the mice were placed into the open field chamber with two identical, non-toxic objects, $12 \mathrm{~cm}$ from the back and sidewalls of the open field box, and $16 \mathrm{~cm}$ apart from each other. A 8 min session, in which the time exploring each object was recorded; an area $2 \mathrm{~cm} 2$ surrounding the object is defined such that nose entries within $2 \mathrm{~cm}$ of the object were recorded as time exploring the object. The animal was then returned to its home cage, and either 24 or $4 \mathrm{~h}$ later, placed into the open field box again. This time, there were two new objects, one identical to the previous objects, and one novel object. The mice were given another 6 min to explore, and the amount of time exploring each object was recorded. Mice that spent $<7 \mathrm{~s}$ exploring the objects were omitted from the analysis [25]. Results were recorded as an object discrimination ratio (ODR), which is calculated by dividing the time the mice spent exploring a novel object, divided by the total amount of time exploring the two objects.

\section{Synaptosomes preparations and Western blot analysis}

For synaptic preparations, isolated hippocampi were homogenized $(\mathrm{w} / \mathrm{v}=10 \mathrm{mg}$ tissue $/ 100 \mathrm{ml}$ buffer $)$ in Hepes-sucrose buffer $(20 \mathrm{mM}$ Hepes/NaOH pH 7.4, 1 mM EDTA, $1 \mathrm{mM}$ EGTA, $0.25 \mathrm{M}$ sucrose) supplemented with protease and phosphatase inhibitors. Homogenates were centrifuged at $800 \mathrm{~g}$ for $10 \mathrm{~min}$. The supernatant (S1) was separated into supernatant (S2) and pellet (P2) by spinning at 9,200 g for $15 \mathrm{~min}$. P2 contains the crude synaptosomal fraction. Synaptosomes fractions were analyzed by western blot using the following antibodies: $\alpha$-APP (22C11/Chemicon) to detect mAPP and imAPP; $\alpha$-APPCTF (Invitrogen/Zymed) to detect $\alpha-C T F$ and $\beta$-CTF; $\alpha$-BRI2 (Santa Cruz) to detect mBri2.

\section{Image scanning and analysis}

WB images were scanned with Epson perfection 3200 Photo scanner and were analyzed with NIH ImageJ software.

\section{Statistical analysis}

All data are shown as mean s.e.m. Statistical tests included two-way ANOVA for repeated measures and $t$-test when appropriate.

\section{Acknowledgments}

This work was supported by grants from the Alzheimer's Association (IIRG-09129984 and ZEN-11-201425 to L.D.), the Edward N. \& Della L. Thome Memorial Foundation grant (to L.D.) and the National Institutes of Health (NIH; R01AG033007 to L.D.).

\section{Authors' contributions}

LD generated the mice. RT performed behavioral experiments. LD performed hippocampal preparations and western blot analysis. LD designed research and wrote the paper. Both authors read and approved the final manuscript.

Received: 30 January 2012 Accepted: 26 April 2012

Published: 26 April 2012

\section{References}

1. De Strooper B, Vassar R, Golde T: The secretases: enzymes with therapeutic potential in Alzheimer disease. Nat Rev Neurol 2010, 6:99-107.

2. Cole SL, Vassar R: The Alzheimer's disease beta-secretase enzyme, BACE1. Mol Neurodegener 2007, 2:22.

3. Bertram L, Lill CM, Tanzi RE: The genetics of Alzheimer disease: back to the future. Neuron 2010, 68:270-281.

4. Vidal R, Frangione B, Rostagno A, Mead S, Revesz T, Plant G, Ghiso J: A stop-codon mutation in the BRI gene associated with familial British dementia. Nature 1999, 399:776-781.

5. St George-Hyslop PH, Petit A: Molecular biology and genetics of Alzheimer's disease. C R Biol 2005, 328:119-130.

6. Matsuda S, Giliberto L, Matsuda Y, Davies P, McGowan E, Pickford F, Ghiso J, Frangione B, D'Adamio L: The familial dementia BRI2 gene binds the Alzheimer gene amyloid-beta precursor protein and inhibits amyloid-beta production. J Biol Chem 2005, 280:28912-28916.

7. Fotinopoulou A, Tsachaki M, Vlavaki M, Poulopoulos A, Rostagno A, Frangione $B$, Ghiso J, Efthimiopoulos S: BRI2 interacts with amyloid precursor protein (APP) and regulates amyloid beta (Abeta) production. J Biol Chem 2005, 280:30768-30772.

8. Matsuda S, Matsuda Y, Snapp EL, D'Adamio L: Maturation of BRI2 generates a specific inhibitor that reduces APP processing at the plasma membrane and in endocytic vesicles. Neurobiol Aging 2011, 32:1400-1408.

9. Matsuda S, Giliberto L, Matsuda Y, McGowan EM, D'Adamio L: BRI2 inhibits amyloid beta-peptide precursor protein processing by interfering with the docking of secretases to the substrate. J Neurosci 2008, 28:8668-8676.

10. Vidal R, Revesz T, Rostagno A, Kim E, Holton J L, Bek T, Bojsen-Moller M, Braendgaard H, Plant G, Ghiso J, et al: A decamer duplication in the 3' region of the $\mathrm{BRI}$ gene originates an amyloid peptide that is associated with dementia in a Danish kindred. Proc Natl Acad Sci U S A 2000, 97:4920-4925.

11. Matsuda S, Tamayev R, D'Adamio L: Increased AbetaPP processing in familial Danish dementia patients. J Alzheimers Dis 2011, 27:385-391.

12. Tamayev R, Matsuda S, Giliberto L, Arancio O, D'Adamio L: APP heterozygosity averts memory deficit in knockin mice expressing the Danish dementia BRI2 mutant. EMBO J 2011, 30:2501-2509.

13. Tamayev R, Matsuda S, Fa M, Arancio O, D'Adamio L: Danish dementia mice suggest that loss of function and not the amyloid cascade causes synaptic plasticity and memory deficits. Proc Natl Acad Sci U S A 2010, 107:20822-20827.

14. Tamayev R, Giliberto L, Li W, d'Abramo C, Arancio O, Vidal R, D'Adamio L: Memory deficits due to familial British dementia BRI2 mutation are caused by loss of BRI2 function rather than amyloidosis. J Neurosci 2010, 30:14915-14924.

15. Tamayev R, Matsuda S, Arancio O, D'Adamio L: beta- but not gamma-secretase proteolysis of APP causes synaptic and memory deficits in a mouse model of dementia. EMBO Mol Med 2011, 4:171-179.

16. Tamayev R, Matsuda S, D'Adamio L: beta - but not gamma-secretase proteolysis of APP causes synaptic and memory deficits in a mouse model of dementia. Mol Neurodegener 2012, 7(Suppl 1):L9.

17. Hardy J, Selkoe DJ: The amyloid hypothesis of Alzheimer's disease: progress and problems on the road to therapeutics. Science 2002, 297:353-356.

18. Jucker M: The benefits and limitations of animal models for translational research in neurodegenerative diseases. Nat Med 2010, 16:1210-1214.

19. Giliberto L, Matsuda S, Vidal R, D'Adamio L: Generation and Initial Characterization of FDD Knock In Mice. PLoS One 2009, 4:e7900. 
20. Saura CA, Choi SY, Beglopoulos V, Malkani S, Zhang D, Shankaranarayana Rao BS, Chattarji S, Kelleher RJ 3rd, Kandel ER, Duff K, et al: Loss of presenilin function causes impairments of memory and synaptic plasticity followed by age-dependent neurodegeneration. Neuron 2004, 42:23-36.

21. Shen J, Kelleher RJ 3rd: The presenilin hypothesis of Alzheimer's disease: evidence for a loss-of-function pathogenic mechanism. Proc Natl Acad Sci U S A 2007, 104:403-409.

22. Zhang C, Wu B, Beglopoulos V, Wines-Samuelson M, Zhang D, Dragatsis I, Sudhof TC, Shen J: Presenilins are essential for regulating neurotransmitter release. Nature 2009, 460:632-636.

23. De Strooper B: Loss-of-function presenilin mutations in Alzheimer disease. Talking Point on the role of presenilin mutations in Alzheimer disease. EMBO Rep 2007, 8:141-146.

24. Mitani Y, Yarimizu J, Saita K, Uchino H, Akashiba H, Shitaka Y, Ni K, Matsuoka $\mathrm{N}$ : Differential Effects between gamma-Secretase Inhibitors and Modulators on Cognitive Function in Amyloid Precursor

Protein-Transgenic and Nontransgenic Mice. J Neurosci 2012, 32:2037-2050.

25. Bevins RA, Besheer J: Object recognition in rats and mice: a one-trial non-matching-to-sample learning task to study 'recognition memory'. Nat Protoc 2006, 1:1306-1311.

doi:10.1186/1750-1326-7-19

Cite this article as: Tamayev and D'Adamio: Inhibition of $\gamma$-secretase worsens memory deficits in a genetically congruous mouse model of Danish dementia. Molecular Neurodegeneration 2012 7:19.

\section{Submit your next manuscript to BioMed Central and take full advantage of:}

- Convenient online submission

- Thorough peer review

- No space constraints or color figure charges

- Immediate publication on acceptance

- Inclusion in PubMed, CAS, Scopus and Google Scholar

- Research which is freely available for redistribution 